\title{
Next-generation drug-eluting stents in coronary artery disease: focus on everolimus-eluting stent (Xience $\mathrm{V}^{\circledR}$ )
}

\author{
Imad Sheiban' \\ Gianluca Villata' \\ Mario Bollati' \\ Dario Sillano' \\ Marzia Lotrionte ${ }^{2}$ \\ Giuseppe Biondi-Zoccai' \\ 'Interventional Cardiology, Division of \\ Cardiology, University of Turin, Turin, \\ Italy; ${ }^{2}$ Institute of Cardiology, Catholic \\ University, Rome, Italy
}

\begin{abstract}
Percutaneous coronary revascularization has been a mainstay in the management of coronary artery disease since its introduction in the late 1970s. Bare-metal stents and, more recently, first-generation drug-eluting stents (DES), such as sirolimus-eluting $\left(\right.$ Cypher $\left.^{\mathbb{R}}\right)$ and paclitaxel-eluting stents $\left(\right.$ Taxus $\left.^{\mathbb{R}}\right)$, have further improved results of percutaneous coronary intervention (PCI) by improving early results and reducing the risk of restenosis. There is currently debate on the safety of these first-generation DES, given the potential for late stent thrombosis, especially after discontinuation of dual antiplatelet therapy. There are well known caveats on the performance of their respective metallic stent platforms, delivery, and dilation systems, and polymer coatings. Second-generation DES, such as zotarolimus-eluting (Endeavor $\left.{ }^{\mathbb{R}}\right)$ and everolimus-eluting stents $\left(\mathrm{Xience}^{\mathrm{Q}}\right)$, have recently become available in the USA and/or Europe. The Xience V stent holds the promise of superior anti-restenotic efficacy as well as long-term safety. In addition, this stent is based on the Multi-link platform and delivery system. Recently available data already suggest the superiority of the Xience $\mathrm{V}$ stent in comparison to the Taxus stent in terms of prevention of restenosis, without significant untoward events. Nonetheless, the number of patients studied and the follow-up duration are still too limited to enable definitive conclusions. Only indirect meta-analyses can be used to date to compare the Xience $\mathrm{V}$ with the Cypher. This systematic review tries to provide a concise and critical appraisal of the data in support of the Xience $\mathrm{V}$ everolimus-eluting stent.
\end{abstract}

Keywords: coronary artery disease, everolimus, percutaneous transluminal coronary angioplasty, stent

\section{Introduction}

\section{Pre-drug-eluting stent (DES) era}

Minimally invasive coronary revascularization by means of percutaneous transluminal angioplasty (PTCA) was introduced in the late 1970s for the management of symptoms of coronary artery disease (Gruntzig 1978; Gruntzig et al 1979). This technology has later expanded its indications, by including also unstable coronary artery disease (Biondi-Zoccai et al 2005a; Burzotta et al 2005) as well as patients with cardiogenic shock (Hochman et al 2001). Stand alone PTCA was, however, fraught with major risks of early abrupt closure, late restenosis due to elastic recoil, constrictive remodeling, and intimal hyperplasia (Fischman et al 1994; Serruys et al 1994). The development of bare-metal stents (BMS) enabled a reduction in the risk of early procedural complications, first and foremost abrupt closure, as well as significantly improving long-term results. However, BMS introduced a new and device-specific iatrogenic condition, ie, in-stent restenosis, mainly due to excessive neointimal proliferation within the stented segment.(Kasaoka et al 1998) A number of systemic treatments have been introduced in order to minimize complications such as in-stent neointimal hyperplasia, but all of them have proved unsuccessful, with the notable but still incompletely tested exception of systemic steroids in carefully selected patients (Versaci et al 2002). 
A paradigm shift has been the development of local anti-restenotic mechanisms; the first among these was brachytherapy. While clearly effective in preventing restenosis at mid-term follow-up, this was, however, significantly limited by edge effects and the risk of late thrombosis, as well as possibly late catch-up in restenosis (Albiero et al 2000a; Leon et al 2001; Waksman et al 2002).

\section{First-generation DES era}

Stemming from innovative but yet suboptimal experiences of local delivery of anti-restenotic radiation (Albiero et al 2000b), the concept of a metallic stent covered with an anti-proliferative drug gained momentum. Despite an initial setback (Grube et al 2004a), this approach was soon proved effective in a number of pivotal trials, thus introducing the DES era. Specifically, results from the RAVEL (Morice et al 2002) and SIRIUS trials (Moses et al 2003) led to the United States Food and Drug Administration (FDA) approval of the sirolimus-eluting stent $\left(\right.$ Cypher $^{\circledR}$, Cordis, Miami, FL, USA), and data from the TAXUS I (Grube et al 2003), II (Colombo et al 2003), and IV (Stone et al 2004) enabled FDA approval of the paclitaxel-eluting stent $\left(\right.$ Taxus $^{\circledR}$, Boston Scientific, Natick, MA, USA). Both these stents were based on a proprietary combination of metallic platform, persistent biocompatible polymer, and anti-proliferative drug.

A large amount of clinical data has been generated focusing on these two DES: a PubMed search updated on 7 September 2007 excluding reviews or editorials - (sirolimus OR paclitaxel) AND stent* AND coronary NOT (editorial[pt] OR review [pt]) - shows that since 1996 as many as 1034 pertinent studies have been published worldwide (Biondi-Zoccai et al 2005b). Although many trials and studies support the overall early and mid-term safety and efficacy of these devices (Hill et al 2004), there has been considerable debate on their long-term safety, especially concerning the potential risk of late stent thrombosis (McFadden et al 2004) as well as late restenosis (Cosgrave et al 2007). The main problem with these first-generation stents has been the risk of late thrombosis, especially after discontinuation of dual antiplatelet therapy (Biondi-Zoccai et al 2006b), whose recommended duration has been extended from 3 months (for Cypher) and 6 months (for Taxus) to 12 months for both, at least according to many authorities (Iakovou et al 2005; Biondi-Zoccai et al 2006b; Airoldi et al 2007; Grines et al 2007).

\section{Second-generation DES era}

All first-generation DES decreased in a clinically and statistically significant fashion angiographic and clinical restenosis compared with BMS, but none of them had all of the following desirable characteristics: a thin, biocompatible (and possibly bioabsorbable) polymer, optimal flexibility, conformability, radiopacity, deliverability and freedom from structural fractures, low late loss, and freedom from hypersensitivity reactions or late thrombotic risk (Hiatt et al 2002; Biondi-Zoccai et al 2005c, 2007). Moreover, competing medical companies are striving to exploit the booming DES market. A second generation of DES has just been developed, and is currently being introduced in clinical practice in Europe and elsewhere, albeit to a lesser extent in the USA. The first of these devices is the Endeavor ${ }^{\text {ID }}$ zotarolimus-eluting stent (Medtronic, Minneapolis, MN, USA), which was tested in the ENDEAVOR I and II trials, showing very few late thromboses and adverse event rates in comparison with the respective BMS (the remarkably effective Driver ${ }^{\circledR}$ [Medtronic]) (Meredith et al 2005; Fajadet et al 2006, 2007). Indeed, the currently available Endeavor stent is based on a phosphorylcholine polymer coating, zotarolimus (formerly ABT-578) and the cobalt-based alloy Driver platform. Despite such promising data, the recent ENDEAVOR III trial has failed to prove non-inferiority of the Endeavor in comparison with the Cypher in terms of late loss and binary restenosis, suggesting that the latter device should be used when thrombosis risk is not major and restenosis needs to be effectively minimized (Kandzari et al 2006). Conversely, preliminary data from the 1500-patient ENDEAVOR IV trial comparing Endeavor vs Taxus have shown similar rates of target vessel failure between these two devices, and have thus enabled FDA approval of the Endeavor stent (Leon 2007).

The other second-generation DES, already approved in Europe and elsewhere but still awaiting FDA approval, is the Xience $\mathrm{V}^{\circledR}$ everolimus-eluting stent (Abbott Laboratories, Abbott Park, IL, USA) (Table 1). The present review aims to summarize basic and clinical evidence available for this device designed for the percutaneous treatment of coronary artery disease. This updated overview exploits a systematic highly sensitive PubMed search strategy: (everolimus OR xience OR promus) AND stent* (updated August 2007). In addition, online databases were checked for unpublished data (Beijk and Piek 2007; Biondi-Zoccai et al 2004).

\section{Design and pharmacology of the Xience $V$ stent and preclinical data Platform}

The platform of the Xience V stent is a L-605 cobalt chromium ( $\mathrm{CoCr}$ ) balloon expandable stent remarkably similar to its successful BMS equivalent, the Multi-Link Vision ${ }^{\circledR}$ 
Table I Currently available drug-eluting stents, with respective manufacturer, stent platform, polymer coating, active drug, mechanism of action, and in-stent late loss (defined as the difference between post-procedural minimum lumen diameter and follow-up minimum lumen diameter, as determined by quantitative angiography)

\begin{tabular}{lllllll}
\hline Stent & Manufacturer & Platform & Polymer & Drug & $\begin{array}{l}\text { Mechanism } \\
\text { of action }\end{array}$ & $\begin{array}{l}\text { In-stent late loss in first- } \\
\text { in-man study at } 6 \text { months }\end{array}$ \\
\hline Champion & Bionsensors & Multi-Link Zeta & Bioabsorbable & Everolimus & Cytostatic & $0.11 \pm 0.23 \mathrm{~mm}(\mathrm{~N}=27)$ \\
Cypher & Cordis & BXVelocity & Persistent & Sirolimus & Cytostatic & $0.16 \pm 0.30 \mathrm{~mm}(\mathrm{~N}=45)$ \\
Endeavor & Medtronic & Driver & Persistent & Zotarolimus & Cytostatic & $0.61 \pm 0.44 \mathrm{~mm}(\mathrm{~N}=100)$ \\
Taxus & Boston Scientific & Express and Liberté & Persistent & Paclitaxel & Cytostatic & $0.36 \pm 0.48 \mathrm{~mm}(\mathrm{~N}=30)$ \\
Xience & Abbott & Multi-LinkVision & Persistent & Everolimus & Cytostatic & $0.10 \pm 0.21 \mathrm{~mm}(\mathrm{~N}=27)$ \\
\hline
\end{tabular}

(Abbott Laboratories), whose main characteristics are low strut thickness, high flexibility and deliverability, acceptable compliance, recoil and risk of plaque prolapse, and overall good radiopacity (Hagemeister et al 2005; Tanimoto et al 2007). The performance of the Multi-Link Vision has already been proved in clinical practice, and this stent is among the most commonly used worldwide (Kaiser et al 2005; Ortolani et al 2007; Xu et al 2007).

\section{Everolimus}

Everolimus (Certican ${ }^{\circledR}$, Novartis, Basel, Switzerland) is an analogue of sirolimus and it has a useful role in the prevention of allograft rejection after organ transplantation. With its anti-proliferative and immunosuppressive actions, the everolimus-FKBP12 complex interferes with FRAP (FKBP12-rapamycin associated protein), a regulatory protein that controls, through the phosphorylation of p70 S6 kinase and 4E-BP1, cell metabolism and proliferation (Carter 2004). Consequentially, FRAP inhibition arrests cell cycle at the late G1 stage (Kahan et al 1999; Grube and Buellesfeld 2004b). Everolimus absorbs to local tissue rapidly and possesses longer cellular residence time and activity. With its potent suppression of reactive neointimal ingrowth, this drug has been shown to significantly reduce of neointimal proliferation (Eisen et al 2003; Grube and Buellesfeld 2004a; Carter et al 2006; Waksman et al 2006). This molecule is thus an ideal agent for the development of a second generation DES.

Moreover, and most recently, other unique properties of everolimus have been reported in an animal atherosclerotic model of coronary stenting. Specifically, Verheye et al have shown that stent-based delivery of everolimus selectively cleared macrophages in rabbit atherosclerotic plaques by autophagy, an mTOR inhibition-dependent and novel mechanism to induce cell death in mammalian cells (Verheye et al 2007). These features would make a device incorporating everolimus an ideal instrument to tackle vulnerable atherosclerotic plaques not yet significantly stenotic but yet prone to rupture and thrombosis (Martinet et al 2007a, b).

\section{Polymer}

Polymer coating in the Xience V stent is formed by two layers: a primer and a drug reservoir, and also by two polymers: an acrylic polymer and a fluoro polymer (Carter et al 2006). The layer of everolimus-polymer matrix with a thickness of 5-6 microns is applied to the surface of the stent and is loaded with $100 \mu \mathrm{g}$ of everolimus per $\mathrm{cm}^{2}$ of stent surface area with no top coat polymer layer (Serruys et al 2005). The first $25 \%$ of stent drug is released during the first day after stent implantation, leading to $75 \%$ release during the first month, and all drug is released within 4 months, with a minimal everolimus systemic level. Overall, the polymer appears highly biocompatible, yet falling short of the other desirable property of being bioabsorbable (Carter et al 2006).

Of interest, coating thickness appears less for the Xience $\mathrm{V}$ (5.3 microns) than for Cypher (7.2 microns) or Taxus (15.6 microns).

\section{Clinical efficacy studies on the Xience $V$ stent SPIRIT I trial}

Besides the favorable results reported on the everolimuseluting stents manufactured by Bionsensors (Biosensors International, Newport Beach, CA, USA) in the FUTURE I (Grube et al 2004b) (Costa et al 2005) and FUTURE II trials,(Tsuchiya et al 2006) the SPIRIT clinical trial program has been the main source of clinical data on the Xience $\mathrm{V}$ stent. (Serruys et al 2005) (Tsuchida et al 2006)

The SPIRIT First-In-Man I study was a single-blind randomized trial performed in 9 centers between December 2003 and April 2004 (Serruys et al 2005). Inclusion criteria were stable or unstable coronary disease, with the exclusion of overt myocardial infarction, plus the presence of a single de novo coronary lesion that was $3.0 \mathrm{~mm}$ in diameter as assessed by on-line quantitative coronary angiography (QCA), that could be covered by an $18 \mathrm{~mm}$ stent, a stenosis of between $50 \%-99 \%$ of the luminal diameter, and a 
Thrombolysis In Myocardial Infarction (TIMI) flow grade of 1 or more. Notably, no patient with unprotected left main, chronic total occlusion, bifurcation lesion, or in-stent restenosis could be included. Patients were thus randomized to the Xience V stent vs a matching Multi-Link Vision stent. A single stent, $3.0 \mathrm{~mm}$ in diameter, $18 \mathrm{~mm}$ long, was used in the study. Double antiplatelet therapy was recommended for 3 months post-procedure. Follow-up was clinical, by QCA and by intravascular ultrasound (IVUS) at 6 months (Biondi-Zoccai et al 2005d; Agostoni et al 2006) The primary endpoint was angiographic in-stent luminal late loss (ie, the difference between post-procedural minimum lumen diameter [MLD] and follow-up MLD, as determined by QCA). Secondary endpoints at 6 months and 1 year included QCA in-stent and in-segment late loss, binary restenosis rate, and percentage diameter stenosis, plus IVUS in-stent percentage volume obstruction.

A total of 28 patients were randomly assigned to receive the everolimus-eluting stent, and 32 were assigned to receive the bare stent. Per-treatment results were reported (27 patients in the everolimus group, and 29 patients in the bare stent group). The mean in-stent late loss, percentage of stenosis, and percentage of patients with 50 percent or more stenosis were $0.10 \mathrm{~mm}, 16 \%$, and $0 \%$, respectively, in the everolimus group, as compared with $0.87 \mathrm{~mm}, 39 \%$, and $25.9 \%$, respectively, in the bare stent group $(\mathrm{p}<0.001$ for late loss and diameter stenosis, $\mathrm{p}=0.01$ for restenosis) (Serruys et al 2005; Tsuchida et al 2006). At IVUS, less neointimal hyperplasia was observed in the everolimus-stent group compared to the bare-stent group $\left(10 \pm 13\right.$ vs $\left.38 \pm 19 \mathrm{~mm}^{3}, \mathrm{p}<0.001\right)$ and similarly, significantly less volume obstruction, $(8.0 \pm$ $10.4 \%$ vs $28.1 \pm 14.0 \%, \mathrm{p}<0.001)$. Concerning clinical efficacy, despite the small sample size, the SPIRIT I trial suggested beneficial effects of the Xience V stent in terms of target vessel failure (1/26 [3.8\%] vs 6/28 [21.4\%] in the BMS group, $\mathrm{p}=0.102)$. However, this difference should be viewed in light of the systematic angiographic follow-up and the inherent risk of oculo-stenotic reflex. Three-year followup data from the SPIRIT I study have just been reported confirming the efficacy and safety of the Xience V stent.

\section{SPIRIT II trial}

The SPIRIT II trial randomized 223 patients to the Xience V and 77 to Taxus. Inclusion criteria were a maximum of two lesions with diameter between 2.5 and 3.75 and length $<28$ $\mathrm{mm}$ (Serruys et al 2006). Follow-up with QCA and IVUS was recommended for all subjects, as the primary end-point of this non-inferiority study was 6-month in-stent late loss.
Indeed, non-inferiority was demonstrated, but data were such that superiority of the Xience V was demonstrated as well. Specifically, in-stent late loss was 0.12 for Xience $V$ and 0.37 for Taxus ( $\mathrm{p}<0.001$ for both superiority and non-inferiority). Similarly, in-stent binary restenosis occurred in 3/237 (1.3\%) vs $3 / 86(3.5 \%, p=0.194)$, and target lesion revascularization in $6 / 223(2.7 \%)$ vs $5 / 77(6.5 \%, p=0.157)$. In addition, cardiac death occurred in $0 / 223$ vs $1 / 77(1.3 \%, p=0.257)$, myocardial infarction in $2 / 223(0.9 \%)$ vs $2 / 77(2.6 \%, p=0.272)$, and stent thrombosis in $1 / 223(0.5 \%)$ vs $1 / 77(1.3 \%, p=0.448)$. Target vessel revascularization was instead not reported.

\section{SPIRIT III trial}

Based on these premises, there were great expectations from the subsequent SPIRIT III trial, a quasi-pivotal study comparing Xience V vs Taxus which was conducted in the US. While data are yet unpublished, they have already been reported at international congresses. A total of 1002 patients with features similar to those enrolled in SPIRIT II were randomized to Xience V $(n=669)$ vs Taxus $(n=333)$. Dual antiplatelet therapy was continued for 6 months. The primary end-point was 6-month in-segment late loss, with pre-specified noninferiority and superiority designs. Major adverse cardiovascular events at 270 days were appraised as secondary end-points. Six-month angiographic follow-up was completed in $77 \%$ of patients ( $n=302$ for Xience $V$ and $n=134$ for Taxus). Insegment late loss proved significantly lower in the Xience $\mathrm{V}$ group than in the Taxus group, $0.14 \pm 0.41 \mathrm{~mm}$ vs $0.28 \pm 0.48$ $\mathrm{mm}$ ( $\mathrm{p}<0.001$ for non-inferiority, $\mathrm{p}=0.004$ for superiority). In-stent late loss was similarly reduced: $0.16 \pm 0.41 \mathrm{~mm}$ vs $0.30 \pm 0.53 \mathrm{~mm}$. Binary restenosis was also lower with Xience $\mathrm{V}$, occurring in $14 / 302(4.7 \%)$ vs $12 / 134(8.9 \%, \mathrm{p}=0.079)$ insegment and 7/302 (2.3\%) vs 8/134 (5.7\%, p=0.083) in-stent. Intriguingly, clinically relevant reductions of end-points were achieved with Xience $\mathrm{V}$, with target lesion revascularization occurring in $17 / 669(2.6 \%)$ vs $17 / 333(5.0 \%, \mathrm{p}=0.035)$, target vessel failure (based on target vessel revascularization) in 48/669 (7.2\%) vs 30/333 (9.0\%, $\mathrm{p}=0.307)$, major adverse cardiovascular events (based on target lesion revascularization) in $31 / 669(4.6 \%)$ vs $30 / 333(8.1 \%, p=0.006)$, and stent thrombosis in $3 / 669(0.5 \%)$ vs $0 / 333(p=0.555)$. Overall, this trial confirmed the positive expectations of previous trials, suggesting the superiority of the Xience V stent in comparison with Taxus in terms of clinical efficacy.

Intriguingly, a meta-analysis of approximately 1300 patients from the SPIRIT II and SPIRIT III clinical trials has indicated that the Xience V system demonstrated superiority over the Taxus stent in angiographic and clinical endpoints, 
with an excellent safety profile (unpublished data). The data for the Xience $\mathrm{V}$ versus the Taxus, respectively were: major adverse cardiovascular events $(4.0 \%$ vs $8.0 \%$, p for superiority $=0.004)$, target lesion revascularization rate $(2.4 \% \mathrm{vs}$ $5.1 \%, \mathrm{p}$ for superiority $=0.01)$, in-stent binary restenosis rate $(1.9 \%$ vs $4.9 \%$, p for superiority $=0.02)$, and in-segment restenosis rate $(4.1 \%$ vs $7.8 \%$, p for superiority $=0.04)$.

\section{Upcoming trials}

Upcoming trials on the Xience V stent include the SPIRIT IV, SPIRIT V and SPIRIT WOMEN trials. Specifically, the SPIRIT IV study will evaluate the safety and efficacy of this DES in comparison to the Taxus stent for the treatment of subjects with up to three de novo native coronary artery lesions, and with a maximum of two lesions per epicardial vessel. This randomized controlled trial will be conducted in the USA and include 1125 patients with coronary artery lesions $2.5-4.25 \mathrm{~mm}$ in diameter and lesion length of $<28$ mm. Clinical follow-up will be at 30, 180, 270 days, and 1, 2, 3, 4, 5 years. The SPIRIT V Clinical Evaluation will be a prospective, single-blind, double arm, randomized multicenter study comparing the Xience V stent vs Taxus in the treatment of diabetic patients with coronary artery lesions (Spirit V Diabetic study), performed in parallel to a prospective, open-label, single arm registry evaluating performance of the Xience V stent in real life use (Spirit V Registry). This multicenter study will enroll approximately 300 patients in the Spirit V Diabetic study in a 2:1 ratio and 2700 patients will be enrolled in the Spirit V Registry. Patients must have lesions between $2.5 \mathrm{~mm}$ and $4.0 \mathrm{~mm}$ in diameter and $\leq 28 \mathrm{~mm}$ in length by visual estimation. Angiographic follow-up will be scheduled at 9 months only for the Spirit V Diabetic study. The primary end point will be in-stent late loss at 270 days. The Spirit V Registry will only include a clinical follow-up and the primary end point will be adjudicated composite rate of all-cause death, myocardial Infarction and target vessel revascularization. Finally, the SPIRIT WOMEN trial will be the first coronary interventional device study focusing on females only. Details are upcoming.

\section{Clinical safety of the $X i e n c e V$ stent}

The safety profile of the Xience $\mathrm{V}$ stent has been to date quite satisfactory, despite the duration of dual antiplatelet therapy limited to the conventional 3-6 months. Specifically, 3-year data from the SPIRIT I trial demonstrated no significant increase in major adverse cardiac events or late stent thrombosis in patients treated with Xience V. Similarly favorable results have been reported from the SPIRIT II (one patient had late stent thrombosis by 6 months in each group) and SPIRIT III trials (stent thrombosis rates at 270 days $0.5 \%$ for Xience V vs 0 for Taxus). Late incomplete apposition (ie, stent malapposition), a phenomenon potentially associated with late stent thrombosis, was similarly uncommon with either Xience V or Taxus in the SPIRIT II and III trials. These findings have enabled European approval of this device, while FDA approval is pending.

The total number of patients treated with Xience $\mathrm{V}$ and the overall follow-up is still too limited to draw definitive conclusions on safety, which have proved quite challenging with first generation DES (Agostoni et al 2007). Some authors have purported an inverse association between late loss and thrombotic risk. Thus, in keeping with this hitherto unproved hypothesis, DES achieving a greater degree of neointimal hyperplasia inhibition, such as the Xience V stent, would be associated with an increased risk of stent thrombosis, at least in comparison to devices which are less aggressive on neointimal hyperplasia (eg, the Endeavor stent). This theory remains however unproven as average neointimal formation and stent strut endothelialization are two separate biological phenomena. Thus, extreme caution should be exercised when inputing lower risk of stent thrombosis with devices associated on average with more late loss (ie, neointimal proliferation). Most recent data from the ENDEAVOR IV trial, showing non-significantly higher rates with the Endeavor stent vs the Taxus stent despite opposite trends for late loss, further call into question the above mentioned hypothesis (Leon 2007).

Nonetheless, in patients similar to those enrolled in the SPIRIT I, II and III trials, we can expect similar efficacy and safety after deployment of a Xience V stent. Whether a longer duration of dual antiplatelet therapy is warranted in selected patients, remains to be clarified (Airoldi et al 2007).

\section{Patient-focused perspective}

Percutaneous coronary revascularization is a mainstay in the management of coronary artery disease. Indeed, PTCA with concomitant stent implantation provides symptomatic benefits in patients with stable coronary artery disease (Hochman et al 2006; Boden et al 2007) which are equivalent to those following coronary artery bypass surgery (Biondi-Zoccai et al 2003), and, on top of that, prognostic benefits in selected higher risk subjects such as those with unstable coronary disease (Biondi-Zoccai et al 2005a; Erne et al 2007). However, the prognostic benefits in stable patients have been recently debated (Hochman et al 2006), and even symptomatic relief may not be persistent in certain groups of patients (Boden et al 2007). Several reasons can 
be advocated, but one of the most common is recurrent flow-limiting stenosis at the target coronary lesion originally treated with PTCA and stenting.

The issue of restenosis has thus been the focus of intensive research since the introduction of PTCA, and DES have come a long way in inhibiting in-stent neointimal hyperplasia while exploiting the mechanical scaffolding properties of the metallic stent platform. On the other hand, DES (including Xience $\mathrm{V})$ are not immune from adverse effects. The most fearsome is stent thrombosis, which if often due to improper stent implantation (Biondi-Zoccai et al 2006a) and/or incomplete endothelialization of stent struts (Biondi-Zoccai et al 2006b). To minimize this risk, prolonged dual antiplatelet therapy with aspirin and a thienopyridine (either clopidogrel or ticlopidine) is routinely recommended after DES implantation, from a minimum of 2 months (in the RAVEL trial focusing on Cypher) (Morice et al 2002) to a maximum of 12 months as currently enforced by international guidelines (Grines et al 2007).

Patients candidate for PTCA with DES implantation should thus be carefully screened for indications and contraindications to such prolonged dual oral antiplatelet therapy. In case of unsuitability for such aggressive antithrombotic therapy, other interventions, including PTCA with BMS or balloon-only, coronary artery bypass, or medical therapy should be considered and decision making individualized.

\section{Conclusions and future perspectives}

The everolimus-eluting Xience $\mathrm{V}$ stent is among the most promising of second generation drug-coated stents designed for the percutaneous treatment of coronary artery disease. Clinical efficacy data are to date quite satisfactory, whereas clinical safety data are promising but yet incomplete as limited only to early and mid-term follow-up ( $\leq 12$ months). If these promises will be fulfilled in further follow-up of completed trials and in upcoming randomized trials and registries, the Xience V stent will surely become a major player in the second-generation DES era.

\section{Disclosures}

Dr. Biondi-Zoccai has consulted for Boston Scientific, Cordis, and Mediolanum Cardio Research, and has received lecture fees from Bristol Myers Squibb.

\section{References}

Agostoni P, Sangiorgi GM, Biondi-Zoccai GG. 2007. Treatment of restenosis with a paclitaxel-coated balloon catheter. $N$ Engl J Med, 356:1071-2; author reply 1072-3.

Agostoni P, Valgimigli M, Abbate A, et al. 2006. Is late luminal loss an accurate predictor of the clinical effectiveness of drug-eluting stents in the coronary arteries? Am J Cardiol, 97:603-5.
Airoldi F, Colombo A, Morici N, et al. 2007. Incidence and predictors of drug-eluting stent thrombosis during and after discontinuation of thienopyridine treatment. Circulation, 116:745-54.

Albiero R, Adamian M, Kobayashi N, et al. 2000a. Short- and intermediateterm results of (32)P radioactive beta-emitting stent implantation in patients with coronary artery disease: The Milan Dose-Response Study. Circulation, 101:18-26.

Albiero R, Nishida T, Adamian M, et al. 2000b. Edge restenosis after implantation of high activity (32)P radioactive beta-emitting stents. Circulation, 101:2454-7.

Beijk MA, Piek JJ. 2007. XIENCE V everolimus-eluting coronary stent system: a novel second generation drug-eluting stent. Expert Rev Med Devices, 4:11-21.

Biondi-Zoccai GG, Abbate A, Agostoni P, et al. 2003. Stenting versus surgical bypass grafting for coronary artery disease: systematic overview and meta-analysis of randomized trials. Ital Heart J, 4:271-80.

Biondi-Zoccai GG, Abbate A, Agostoni P, et al. 2005a. Long-term benefits of an early invasive management in acute coronary syndromes depend on intracoronary stenting and aggressive antiplatelet treatment: a metaregression. Am Heart J, 149:504-11.

Biondi-Zoccai GG, Agostoni P, Abbate A, et al. 2005b. A simple hint to improve Robinson and Dickersin's highly sensitive PubMed search strategy for controlled clinical trials. Int J Epidemiol, 34:224-5.

Biondi-Zoccai GG, Agostoni P, Abbate A, et al. 2005c. Adjusted indirect comparison of intracoronary drug-eluting stents: evidence from a metaanalysis of randomized bare-metal-stent-controlled trials. Int $J$ Cardiol, 100:119-23.

Biondi-Zoccai GG, Agostoni P, Sangiorgi GM, et al. 2006a. Incidence, predictors, and outcomes of coronary dissections left untreated after drug-eluting stent implantation. Eur Heart J, 27:540-6.

Biondi-Zoccai GG, Chieffo A, Agostoni P, et al. 2005d. Applying intravascular ultrasound to optimize the placement of coronary drug-eluting stents. Minerva Cardioangiol, 53:165-76.

Biondi-Zoccai GG, Lotrionte M, Abbate A, et al. 2007. Direct and indirect comparison meta-analysis demonstrates the superiority of sirolimusversus paclitaxel-eluting stents across 5854 patients. Int $J$ Cardiol, 114:104-5.

Biondi-Zoccai GG, Lotrionte M, Agostoni P, et al. 2006b. A systematic review and meta-analysis on the hazards of discontinuing or not adhering to aspirin among 50,279 patients at risk for coronary artery disease. Eur Heart J, 27:2667-74.

Biondi-Zoccai GG, Testa L, Agostoni P. 2004. A practical algorithm for systematic reviews in cardiovascular medicine. Ital Heart J, 5:486-7.

Boden WE, O'Rourke RA, Teo KK, et al. 2007. Optimal medical therapy with or without PCI for stable coronary disease. $N$ Engl J Med, 356:1503-16.

Burzotta F, Trani C, RomagnolI E, et al. 2005. Manual thrombus-aspiration improves myocardial reperfusion: the randomized evaluation of the effect of mechanical reduction of distal embolization by thrombusaspiration in primary and rescue angioplasty (REMEDIA) trial. $J$ Am Coll Cardiol, 46:371-6.

Carter AJ. 2004. TOR of the cell cycle: Are there important implications for diabetics in the era of the drug-eluting stent? Catheter Cardiovasc Interv, 61:233-6.

Carter AJ, Brodeur A, Collingwood R, et al. 2006. Experimental efficacy of an everolimus eluting cobalt chromium stent. Catheter Cardiovasc Interv, 68:97-103.

Colombo A, Drzewiecki J, Banning A, et al. 2003. Randomized study to assess the effectiveness of slow- and moderate-release polymer-based paclitaxel-eluting stents for coronary artery lesions. Circulation, 108:788-94.

Cosgrave J, Corbett SJ, Melzi G, et al. 2007. Late restenosis following sirolimus-eluting stent implantation. Am J Cardiol, 100:41-4.

Costa RA, Lansky AJ, Mintz GS, et al. 2005. Angiographic results of the first human experience with everolimus-eluting stents for the treatment of coronary lesions (the FUTURE I trial). Am J Cardiol, 95:113-6. 
Eisen HJ, Tuzcu EM, Dorent R, et al. 2003. Everolimus for the prevention of allograft rejection and vasculopathy in cardiac-transplant recipients. N Engl J Med, 349:847-58.

Erne P, Schoenenberger AW, Burckhardt D, et al. 2007. Effects of percutaneous coronary interventions in silent ischemia after myocardial infarction the SWISSI II randomized controlled trial. JAMA, 297:1985-91.

Fajadet J, Wijns W, Laarman GJ, et al. 2006. Randomized, doubleblind, multicenter study of the Endeavor zotarolimus-eluting phosphorylcholine-encapsulated stent for treatment of native coronary artery lesions: clinical and angiographic results of the ENDEAVOR II trial. Circulation, 114:798-806.

Fajadet J, Wijns W, Laarman GJ, et al. 2007. Randomized, doubleblind, multicenter study of the Endeavor zotarolimus-eluting phosphorylcholine-encapsulated stent for treatment of native coronary artery lesions. Clinical and angiographic results of the ENDEAVOR II Trial. Minerva Cardioangiol, 55:1-18.

Fischman DL, Leon MB, Baim DS, et al. 1994. A randomized comparison of coronary-stent placement and balloon angioplasty in the treatmen of coronary artery disease. Stent Restenosis Study Investigators N Engl J Med, 331:496-501.

Grines CL, Bonow RO, Casey DE Jr, et al. 2007 Prevention of premature discontinuation of dual antiplatelet therapy in patients with coronary artery stents: a science advisory from the American Heart Association, American College of Cardiology, Society for Cardiovascular Angiography and Interventions, American College of Surgeons, and American Dental Association, with representation from the American College of Physicians. Circulation, 115:813-8.

Grube E, Buellesfeld L. 2004a. Everolimus for stent-based intracoronary applications. Rev Cardiovasc Med, 5(Suppl 2):S3-8.

Grube E, Buellesfeld L. 2004b. Rapamycin analogs for stent-based local drug delivery. Everolimus- and tacrolimus-eluting stents. Herz, 29:162-6.

Grube E, Lansky A, Hauptmann KE, et al. 2004a. High-dose 7-hexanoyltaxoleluting stent with polymer sleeves for coronary revascularization one-year results from the SCORE randomized trial. J Am Coll Cardiol, 44:1368-72.

Grube E, Silber S, Hauptmann KE, et al. 2003. TAXUS I: six- and twelvemonth results from a randomized, double-blind trial on a slow-release paclitaxel-eluting stent for de novo coronary lesions. Circulation, 107:38-42.

Grube E, Sonoda S, Ikeno F, et al. 2004b. Six- and twelve-month results from first human experience using everolimus-eluting stents with bioabsorbable polymer. Circulation, 109:2168-71.

Gruntzig A. 1978. Transluminal dilatation of coronary-artery stenosis. Lancet, 1:263.

Gruntzig AR, Senning A, Siegenthaler WE. 1979. Nonoperative dilatation of coronary-artery stenosis: percutaneous transluminal coronary angioplasty. $N$ Engl J Med, 301:61-8.

Hagemeister J, Baer FM, Schwinger RH, et al. 2005. Compliance of a cobalt chromium coronary stent alloy - the COVIS trial. Curr Control Trials Cardiovasc Med, 6:17.

Hiatt BL, Ikeno F, Yeung AC, et al. 2002. Drug-eluting stents for the prevention of restenosis: in quest for the Holy Grail. Catheter Cardiovasc Interv, 55:409-17.

Hill RA, Dundar Y, Bakhai A, et al. 2004. Drug-eluting stents: an early systematic review to inform policy. Eur Heart J, 25:902-19.

Hochman JS, Lamas GA, Buller CE, et al. 2006. Coronary intervention for persistent occlusion after myocardial infarction. $N$ Engl $\mathrm{J} \mathrm{Med}$, 355:2395-407.

Hochman JS, Sleeper LA, White HD, et al. 2001. One-year survival following early revascularization for cardiogenic shock. JAMA 285:190-2.

Iakovou I, Schmidt T, Bonizzoni E, et al. 2005. Incidence, predictors, and outcome of thrombosis after successful implantation of drug-eluting stents. JAMA, 293:2126-30

Kahan BD, Wong RL, Carter C, et al. 1999. A phase I study of a 4-week course of SDZ-RAD (RAD) quiescent cyclosporine-prednisone-treated renal transplant recipients. Transplantation, 68:1100-6.
Kaiser C, Brunner-La Rocca HP, Buser PT, et al. 2005. Incremental cost-effectiveness of drug-eluting stents compared with a thirdgeneration bare-metal stent in a real-world setting: randomised Basel Stent Kosten Effektivitats Trial (BASKET). Lancet, 366:921-9.

Kandzari DE, Leon MB, Popma JJ, et al. 2006. Comparison of zotarolimuseluting and sirolimus-eluting stents in patients with native coronary artery disease: a randomized controlled trial. J Am Coll Cardiol, 48:2440-7.

Kasaoka S, Tobis JM, Akiyama T, et al. 1998. Angiographic and intravascular ultrasound predictors of in-stent restenosis. $J$ Am Coll Cardiol, $32: 1630-5$.

Leon MB. 2007. Endeavor clinical trial program [online]. Accessed 16 October 2007. URL: http://www.crtonline.org/flash.aspx?PAGE_ ID $=4728$.

Leon MB, Teirstein PS, Moses JW, et al. 2001. Localized intracoronary gamma-radiation therapy to inhibit the recurrence of restenosis after stenting. N Engl J Med, 344:250-6.

Martinet W, Verheye S, De Meyer GR. 2007a. Everolimus-induced mTOR inhibition selectively depletes macrophages in atherosclerotic plaques by autophagy. Autophagy, 3:241-4

Martinet W, Verheye S, De Meyer, GR. 2007b. Selective depletion of macrophages in atherosclerotic plaques via macrophage-specific initiation of cell death. Trends Cardiovasc Med, 17:69-75.

McFadden EP, Stabile E, Regar E, et al. 2004. Late thrombosis in drugeluting coronary stents after discontinuation of antiplatelet therapy. Lancet, 364:1519-21.

Meredith I, Ormiston J, Whitbourn R, et al. 2005. First-in-human study of the endeavor zotarolimus-eluting phosphorylcholine-encapsulated stent system in de novo native coronary artery lesions: Endeavor I trial. EuroIntervention, 1:157-64.

Morice MC, Serruys PW, Sousa JE, et al. 2002. A randomized comparison of a sirolimus-eluting stent with a standard stent for coronary revascularization. $N$ Engl J Med, 346:1773-80.

Moses JW, Leon MB, Popma JJ, et al. 2003. Sirolimus-eluting stents versus standard stents in patients with stenosis in a native coronary artery. N Engl J Med, 349:1315-23.

Ortolani P, Marzocchi A, Marrozzini C, et al. 2007. Randomized comparative trial of a thin-strut bare metal cobalt-chromium stent versus a sirolimus-eluting stent for coronary revascularization. Catheter Cardiovasc Interv, 69:790-8.

Serruys P, Ong A, Piek JJ, et al. 2005. A randomized comparison of a durable polymer everolimus-eluting stent with a bare metal coronary stent: The SPIRIT first trial. EuroIntervention, 1:58-65.

Serruys P, Ruygrok P, Neuzner J, et al. 2006. A randomised comparison of an everolimus-eluting coronary stent with a paclitaxel-eluting coronary stent: the SPIRIT II trial. EuroIntervention, 2:286-94.

Serruys PW, De Jaegere P, Kiemeneij F, et al. 1994. A comparison of balloon-expandable-stent implantation with balloon angioplasty in patients with coronary artery disease. Benestent Study Group. $N$ Engl J Med, 331:489-95.

Stone GW, Ellis SG, Cox DA, et al. 2004. A polymer-based, paclitaxeleluting stent in patients with coronary artery disease. $N$ Engl $J$ Med, 350:221-31

Tanimoto S, Serruys PW, Thuesen L, et al. 2007. Comparison of in vivo acute stent recoil between the bioabsorbable everolimus-eluting coronary stent and the everolimus-eluting cobalt chromium coronary stent: Insights from the ABSORB and SPIRIT trials. Catheter Cardiovasc Interv, 70:515-23.

Tsuchida K, Garcia-Garcia HM, Ong AT, et al. 2006. Revisiting late loss and neointimal volumetric measurements in a drug-eluting stent trial: analysis from the SPIRIT FIRST trial. Catheter Cardiovasc Interv, 67:188-97.

Tsuchiya, Y., Lansky, A. J., Costa, R. A., et al. (2006) Effect of everolimuseluting stents in different vessel sizes (from the pooled FUTURE I and II trials). Am J Cardiol, 98, 464-9.

Verheye S, Martinet W, Kockx MM, et al. 2007. Selective clearance of macrophages in atherosclerotic plaques by autophagy. $\mathrm{J}$ Am Coll Cardiol, 49:706-15. 
Versaci F, Gaspardone A, Tomai F, et al. 2002. Immunosuppressive Therapy for the Prevention of Restenosis after Coronary Artery Stent Implantation (IMPRESS Study). J Am Coll Cardiol, 40:1935-42.

Waksman R, Ajani AE, White RL, et al. 2002. Intravascular gamma radiation for in-stent restenosis in saphenous-vein bypass grafts. $N$ Engl $J$ Med, 346:1194-9.

Waksman R, Pakala R, Baffour R, et al. 2006. Optimal dosing and duration of oral everolimus to inhibit in-stent neointimal growth in rabbit iliac arteries. Cardiovasc Revasc Med, 7:179-84.

Xu YW, Wei YD, Tang K, et al. 2007. Multi-link Vision and MiniVision stent registry in Asian patients with coronary artery disease: a prospective, multi-center study. Chin Med J (Engl), 120:1093-6. 